\title{
Wind power costs expected to decrease due to technological progress
}

Eric Williams ${ }^{1 *}$,Eric Hittinger ${ }^{2}$, Rexon Carvalho ${ }^{1}$, Ryan Williams

1. Golisano Institute for Sustainability, Rochester Institute of Technology, 1 Lomb Memorial Dr. Rochester, NY 14623

2. Department of Public Policy, Rochester Institute of Technology, 1 Lomb Memorial Dr. Rochester, NY 14623

Corresponding author: Eric Williams, Golisano Institute for Sustainability, Rochester Institute of Technology, 1 Lomb Memorial Dr., Rochester, NY 14623, Phone: +1-585-475-7211. Email: exwgis@ rit.edu

Keywords: Wind Energy, Technological Progress, Cost Trends, Forecasting, Energy Policy

\begin{abstract}
:
The potential for future cost reductions in wind power affects adoption and support policies. Prior analyses of cost reductions give inconsistent results. The learning rate, or fractional cost reduction per doubling of production, ranges from $-3 \%$ to $+33 \%$ depending on the study. This lack of consensus has, we believe, contributed to high variability in forecasts of future costs of wind power. We find that learning rate can be very sensitive to the starting and ending years of datasets and the geographical scope of the study. Based on a single factor experience curve that accounts for capacity factor gains, wind quality decline, and exogenous shifts in capital costs, we develop an improved model with reduced temporal variability. Using a global adoption model,
\end{abstract}

(C) 2017. This manuscript version is made available under the Elsevier user license http://www.elsevier.com/open-access/userlicense/1.0/ 
the wind-learning rate is between $7.7 \%$ and $11 \%$, with a preferred estimate of $9.8 \%$. Using global scenarios for future wind deployment, this learning rate range implies that the cost of wind power will decline from 5.5 cents/kWh in 2015 to $4.10-4.40$ cents/kWh in 2030 , lower than a number of other forecasts. If attained, wind power may be the cheapest form of new electricity generation by 2030, suggesting that support and investment in wind should be maintained or expanded. 


\section{Background}

The declining costs of solar photovoltaics is a well-known phenomenon used in advocating for continued government support for the technology. Past and future cost reductions for wind power, in contrast, are under more contention. In 2015, wind produced 8 times as much energy as solar at $60 \%$ of the cost, putting it close to price parity with traditional technologies (EIA 2015; EIA 2016; Wiser and Bolinger 2015). Since the turn of the century, the wind industry has experienced rapid growth and improving economic competitiveness (Wiser and Bolinger 2015). However, over this time, stagnating capital costs have raised concerns that wind has matured and further investments will not yield significant cost reductions (Bolinger and Wiser 2011).

In this work we forecast wind power cost, developing empirical models that reproduce historical cost trends. Forecasting cost reductions due to technological progress is usually done through experience curves and learning rates. The experience curve is the observed power law decline in a characteristic relative to the cumulated experience of that characteristic's process (Wright 1936; Arrow 1962). In energy economics, the single factor experience curve takes the form:

$$
C=C_{0}\left(P / P_{0}\right)^{-\alpha}
$$

where $\mathrm{C}$ is price per unit, $\mathrm{P}$ is the units produced, $\mathrm{C}_{0}$ and $\mathrm{P}_{0}$ are initial cost and production values, and $\alpha$ is the learning coefficient. The learning coefficient $\alpha$ is used to find the cost 
reduction for each doubling of cumulative output. This also called the learning rate (LR) and is illustrated in the equation:

$$
L R=1-2^{-\alpha}
$$

Originally, the learning rate was used to identify cost reductions from increasing experience in an airplane manufacturing plant (Wright 1936). Since this early work, the learning rate has been used to explain cost reductions for a wide variety of technologies. While generalizations of equation (1) that include two or more factors have been developed, the single factor learning curve measures aggregate progress with fewer input parameters, e.g. research and development investments. Despite its simplicity, the single factor experience curve equation (1) fits empirical data surprisingly well. Nagy et al (2013) showed that R-squared exceeds $90 \%$ for a majority of 62 investigated technologies.

Recent reviews of the energy experience curve literature found large variations in the range of reported learning rates (Lindman and Söderholm 2012; Rubin et al 2015). The range of learning rate estimates for wind power was particularly high, ranging from $-3 \%$ to $33 \%$ (Ibid). A negative learning rate implies that wind power is getting more expensive over time, while a $33 \%$ learning rate denotes extremely rapid declines in wind electricity cost as more is produced. Figure 1 illustrates the combined results of two meta-analyses for wind learning rates and highlights the lack of consensus from 120 different analyses. This lack of consensus could convince some that the learning rate approach is not suitable for wind power.

<figure 1 approximately here>

Summarizing prior work on retrospective modeling of wind costs, a 2000 report from the International Energy Agency reviewed the then-current state of wind experience curves (e.g. Neij 
1999) and included new estimates (IEA 2000). A wide variety of wind learning rates are reported, from 4\% for Denmark (1982-1997), to 18\% in the European Union (1980-1995), to $32 \%$ in the US (1984-1994), though the reasons for these stark differences were not explained. Using capital cost $(\$ / \mathrm{W})$ as the dependent variable, the Wind Technology Market Report series has learning rate results for different time periods, e.g. 8.3\% for 1982- 2010 and $14.4 \%$ for 19822004 (Wiser and Bolinger 2015). There are many additional studies for different regions and time periods, e.g. (McDonald and Schrattenholzer 2001; Ibenholt 2002; Junginger et al. 2009). There are also multi-factor learning curve studies separating cost reductions into learning-bydoing and learning-by-research (Miketa and Schrattenholzer 2004; Klaassen et al. 2005; Jamasb and Köhler 2007; Söderholm and Klaassen 2007; Ek and Söderholm 2010). Learning-by-doing rates vary from 1-17\%, learning-by-research varies from 5\% to $27 \%$. Most prior analyses use capital cost $(\$ / \mathrm{kW})$ as the dependent variable. A notable exception is (Neij et al 2003), who found differences in learning rate using capital cost $(\$ / \mathrm{kW})$ versus Levelized Cost of Electricity (LCOE) $(\$ / \mathrm{kWh})$ measures.

Forecasting wind power costs draws from a number of approaches, including experience curves, engineering models, expert elicitation and scenario analysis. (Lantz et al 2012) synthesized outcomes of 18 scenarios from different regions for wind cost reductions. Results ranged from $0 \%$ to $40 \%$ reduction to 2030 , with a $20 \%-30 \%$ reduction in cost representing the 20th to 80th percentiles of the scenarios. Part of our goal is to compare our analytical results with governmental expectations for reductions in wind cost. Focusing on the United States, the primary articulation of governmental understanding of energy systems is the Annual Energy Outlook (AEO) from the Energy Information Administration (EIA 2014). AEO forecasts are powered the by National Energy Modeling System (NEMS), a techno-economic model of the 
U.S. energy system with interacting modules describing supply and demand for electricity, fossil and bio-fuels (EIA 2016a). The forecasting perspective for wind is summarized in this excerpt from Assumptions to the AEO 2015: "Capital costs for wind technologies are assumed to increase in response to: (1) declining natural resource quality ... (2) increasing costs of upgrading existing local and network ..., and (3) market conditions, such as the increasing costs of alternative land uses..." (EIA 2015a). Results are consistent with this perspective: AOE 2015 forecasts the LCOE of wind to be $\$ 73.6 / \mathrm{MWh}$ in 2020, increasing to $\$ 75.1 / \mathrm{MWh}$ in 2040 (both in 2013 US\$) (EIA 2015b).

A different section of the U.S. DOE, the Wind and Water Power Technologies Office, has sponsored the Wind Technology Market Report series since 2008 (Wiser and Bolinger 2015 and earlier) and recently, a Wind Vision study (DOE 2015). The Wind Vision study considers technological progress, geographical distribution of wind resources, and economic background factors to build a scenario of wind adoption in the U.S. From the results, learning rates for onshore wind can be inferred as $6 \%$ in the base case, with $0 \%$ and $11 \%$ for pessimistic and optimistic cases respectively. In summary, the main energy model informing the U.S. government forecasts small increases in wind cost and the wind specialists within DOE forecast modest decreases. This review of the U.S. situation underscores pervasive and important questions for energy policy: What expectations do governments have for technological progress? How were these expectations developed? How do they affect energy policy decisions?

Despite a long history of research on the wind experience curve and cost forecasting, there is still a need to better understand the disagreement and improve the empirical basis for model choice. We investigate three issues central to the wind experience curve: temporal "stochasticity", geographical boundaries and model structure. 
Temporal "stochasticity" refers to variability in model results with different start and end years for data-sets. The ideal start year of a technological progress model for wind power depends on the particular institutional context in the region of interest. While analysts strive to gather as much data as possible, it is generally impractical to retroactively gather data for wind projects built decades in the past. The end year of a data-set depends on when a study is done, typically a year or two prior to the analysis.

As analysts generally have little control over the earlier start and latest end-years of data sets, we treat these as variables and explore how learning rate results changes as a function of different temporal bounding within the available data.

Geographical boundaries refer to choices in regional aggregations used in modeling. Many prior studies have analyzed wind power trends at the national level, e.g. for China (Qiu and Anadon 2012), the U.S. (IEA 2000) and even a national sub-region (California) (McDonald and Schrattenholzer 2001)). There have also been global studies (e.g. Junginger et al 2005, 2009), though data limitations have led to national prices used as proxies for global values.

A national experience curve model would be appropriate if wind technology were separately developed within each nation. While portions of the cost of a wind farm are more local in nature, e.g. construction, the wind industry is a highly globalized one, with multinational firms dominating production (Navigant 2015). Some future experience curve model, enabled by as yet unavailable data, might succeed in resolving how different cost components fall according to different scales of geographical activity. However, given current data availability, the global nature of the wind industry suggests that a global experience curve is the most appropriate choice. 
A global experience curve has the following form:

$$
C(G P)=C_{0}\left(G P / G P_{0}\right)^{-\alpha_{g}}=C_{0}\left(\sum P^{j} / \sum P_{o}^{j}\right)^{-\alpha_{g}}
$$

Where the global cumulative production of wind power, GP, can also be expressed as a sum over cumulative production $\mathrm{P}^{\mathrm{j}}$ in $\mathrm{j}$ nations, and $\alpha_{g}$ is a global learning rate. Ideally, $\mathrm{C}_{0}$ is global average cost, but lack of a consistent global dataset implies that national values need to be used as a proxy.

Comparing the global experience curve of equation (3) to national-level data will result in different apparent learning rates depending on the relative rate of adoption in that country. If the production $\left(\mathrm{P}^{\mathrm{j}}\right)$ in a nation tracks global trends, the global and national models would yield similar results. If however, production in nation $\mathrm{j}$ grows slower than the rest of the world, this will result in an apparent learning rate higher than $\alpha_{g}$. In other words, the learning contribution due to other nations' activities will artificially inflate the rate of cost reductions seen in nation $\mathrm{j}$. Conversely, if wind adoption in nation $\mathrm{j}$ is growing more rapidly than the rest of the world, the calculated national learning rate will be lower than $\alpha_{g}$. To address this geographical dependency, we build both a global and a U.S. experience curve and compare the results. Model structure: We consider three issues for the structure of a wind experience curve model: 1. Energy Cost $(\$ / \mathrm{kWh})$ vs. Power Capacity Cost $(\$ / \mathrm{kW})$ : We use energy generated $(\$ / \mathrm{kWh})$ to measure wind cost, not installed power capacity $(\$ / \mathrm{kW})$, as this better describes the target towards which improvements have been focused. In most of the prior literature on learning for generation technologies, the dependent variable is capital cost $(\$ / \mathrm{kW})$, with the independent variable being installed power capacity $(\mathrm{kW})$. For wind, this means that the focus is on rated 
power, not actual turbine performance. However, the wind industry is driven to reduce net energy production costs $(\$ / \mathrm{kWh})$, not just the capacity-based capital cost of the turbines. Lower energy production costs have been achieved through improved efficiency, cut-in speed, and hub height (Krohn et al 2009). For example, average hub height has increased from 55M to 80M and wind capacity factors have improved from 30\% to 35\% in the last 15 years (Wiser and Bolinger 2015). These technological advances reduced the cost of producing wind energy with little impact on turbine capital costs. Indeed, the trend towards taller and larger capacity turbines, called upscaling, tends to increase capital cost $(\$ / \mathrm{kW})$ in order to realize higher capacity factors and lower energy costs $(\$ / \mathrm{kWh})$.

2. Wind Quality Adjusted Energy: We also address wind quality issues that mask the rate of technological progress. The first issue is that annual variability in weather leads to some years with better wind resource than others. This natural year-to-year wind variation yields capacity factor changes unrelated to technological progress (Katzenstein et. al 2010). By averaging multiyear trends in capacity factor, an estimate of technology-driven capacity factor improvements is found. Second, there is year-by-year variability in the quality of new wind sites. A lower quality site results in lower capacity factor, a reduction unrelated to the state of wind technology. We account for the changing quality of sites by adjusting observed capacity factors upwards assuming all new sites had the same wind quality with respect to the reference year 1999. For example, using the Lawrence Berkeley National Lab's (LBNL) wind quality index (Wiser and Bolinger 2015), the observed 2013 average capacity factor of 33\% increases to $41 \%$ if the turbine had been placed on a 1999 quality site.

3.Exogenous fluctuations in capital cost: The final step addresses exogenous fluctuations in capital cost factors. As reported by Bolinger and Wiser in their 2011 paper, the rise in capital 
costs during the 2002-2010 period can partly be explained by exogenous factors such as rising cost of steel and a weak U.S. dollar. Because these cost increases are unrelated to technological progress, they should be removed from the experience curve. We expand the methodology from the paper (Bolinger and Wiser 2011) to account for more trading partners and material costs.

We thus develop four experience curve models:

- A: Capacity model - capital cost $(\$ / \mathrm{W})$ versus total capacity (W)

- B: Generation model - levelized cost of electricity $(\$ / \mathrm{kWh})$ vs. cumulative generation (kWh)

- C: Wind-quality adjusted generation model: levelized cost assuming same wind site quality $(\$ / \mathrm{kWh})$ vs. cumulative generation $(\mathrm{kWh})$

- D: Full model, Capital cost and wind-quality adjusted - levelized cost assuming same wind site quality $\&$ adjusted exogenous capital fluctuations $(\$ / \mathrm{kWh})$ vs. cumulative generation $(\mathrm{kWh})$

Our hypothesis is that temporal stochasticity and geographical boundaries can explain the variance in prior learning rate results. We empirically construct the four models (described above) based on U.S. data for wind costs and U.S. and global data for production. Given the lack of global cost time series data, a national cost proxy is needed. The U.S. is an attractive choice for proxy due to a large and consistent market and the availability of wind data back to the early 1980’s.

We explore the performance of the four models with respect to sensitivity to changing start and end-years of data-sets and standard regression considerations. The goal is to find an empirically robust experience model with lower sensitivity to the range of dates chosen for the 
source data. We will also consider how learning rates differ considering global versus U.S. production data.

\section{Data}

Data sources: Data needed to implement the proposed models include capital cost $(\$ / \mathrm{kW})$, operation and maintenance $(\mathrm{O} \& \mathrm{M})$ cost $(\$ / \mathrm{kWh}$ or $\$ / \mathrm{kW}$-year), capacity expansions $(\mathrm{kW})$ and wind generation $(\mathrm{kWh})$ We prefer to construct a retrospective model that describes as long a historical period as is feasible, both for completeness of data and to allow a wide range from which to select different date range subsets for comparison.

In the U.S., the Wind Technology Market Report (WTMR) series has data on capital costs, O\&M costs, and capacity expansions from the early 1980's onwards, though there are occasional gaps in the data (WTMR 2015 and earlier years). We use the term capital cost to refer to WTMR's installed project cost, which generally reflect turbine purchase and installation, balance of plant, and any substation and/or interconnection expenses (Ibid). U.S. annual generation from wind power from 1984 is available from the Energy Information Administration (EIA 2016). 1999 initiates a period of modern wind expansion and the beginning of a number of relevant datasets, such as adjusted capital cost (Bolinger and Wiser 2011), the LBNL wind site index (Wiser and Bollinger 2015) and O\&M cost data (Wiser and Bolinger 2015).

At the global level, capacity and generation data are available from the Wind Power Working Group of the International Energy Agency (IEA 2015) and the Global Wind Energy Council (GWEC 2016). The Energy Information Administration also publishes global wind generation data starting in the year 1983 (EIA 2016c). The three databases show comparable numbers in overlapping years. 
We develop the capacity model (A) for 1984-2015 and the other three models (B, C, D) from 1990-2015. All data points are adjusted to 2015 USD and available via a spreadsheet in the supplementary information.

Data adjustments for capital and operations and maintenance $(O \& M)$ costs:

Capital and O\&M costs require careful treatment due to limited data for earlier years. The U.S. data source covering the longest period is the Wind Technologies Market Report (WTMR) from Lawrence Berkeley National Laboratory (LBNL) (Wiser and Bolinger 2015).

Considering capital costs first, Figure 40 in WTMR 2015 shows individual plant capital costs $(\$ / \mathrm{kW})$ and weighted averages for a total of 789 projects over the time period 1982-2015. It is important to note, however, that the majority of data points are from projects after 1998. From the period 1982-1997 there are a total of 15 projects, and no projects at all are reported for the years 1984 and 1991-93. Furthermore, there is considerable variability in capital costs within a given year.

To address the lack of data for earlier years, we separate the dataset into two time periods: 19891998 and 1999-2013. For the latter, given sufficient data points in each year, we directly use the annual weighted average for each year. For the former, however, it would be inappropriate to use data from one or two plants in a given year to represent a national cost trend. For the period 1982-1998, we thus perform a regression using 1989-1998 data. While this smoothes out the raw data (which fluctuate up to $+/-50 \%$ year-to-year), we argue that it gives a more accurate presentation of the true trends in average capital cost. The results of this data processing are 
shown in the Table 1 below. The full dataset for 1984-2015 (both raw and processed data) is provided in the Supplemental Information worksheet.

<Table 1 approximately here>

Operations and Maintenance $(O \& M)$ Cost:

The Wind Technology Market Report gives O\&M costs from 1982-2015. However, variability by project and over time is covered very differently for different years. Pre-1998 data is sparse, with data on 0-4 projects each year for 1982-1997. Similar to the above for capital costs, a regression model is done, resulting in O\&M costs that start at $\$ .03 / \mathrm{kWh}$ in 1990 falling to $\$ .019 / \mathrm{kWh}$ in 1997. After 1998, when more O\&M data become available, we use Figure 46 in WTMR 2015 (Wiser and Bollinger 2015), extrapolating data for years when O\&M are not given. The resulting O\&M costs fall from $\$ .019 / \mathrm{kWh}$ in 1998 to $\$ .011 / \mathrm{kWh}$ in 2015 .

These results show a clear trend towards reduction in O\&M costs. To examine the sensitivity of learning rate on declining $\mathrm{O} \& \mathrm{M}$ costs, we also tested a scenario that included a constant $\mathrm{O} \& \mathrm{M}$ cost of $\$ 50 / \mathrm{kW}$-year for all years (detailed results appear in the supplemental information). This assumption reduces learning rates by only $1 \%$.

\section{Methods}

\section{Functional Unit: Power Capacity Cost $(\$ / k W)$ to Energy Cost $(\$ / k W h)$}

We develop data and models to describe retrospective trends in capital cost (or power capacity cost) and Levelized Cost of Energy (or Energy Cost). As our goal is to identify the learning rate of progress in wind generation, we intentionally quantify and control for additional factors that affect actual wind generation costs (such as financing, location-based wind resource, or 
fluctuations in materials costs). We use data that aggregates multiple sites (WTMR 2015 and earlier years) and do not attempt to capture site variability. Our cost results are thus not intended to inform the economics of a wind generation plant built in a particular location. Also, we neglect financing costs, typically $1-5 \%$ of capital costs (Schwabe et al 2011), on the grounds that these are expected to be independent of technological progress.

The first treatment for the model is to move the analytical focus from capital cost $(\$ / \mathrm{kW})$ and cumulative power capacity $(\mathrm{kW})$ to energy cost $(\$ / \mathrm{kWh})$ and cumulative energy production $(\mathrm{kWh})$, a better reflection of the goal pursued by technological improvements of wind turbines. The cost portion uses the Levelized Cost of Electricity (LCOE) to represent lifetime costs of a power plant per total energy output. The cost function takes the form:

$$
L C O E_{t}=\frac{\left(K_{t} * C A P_{t}+\sum_{i=1}^{L} \frac{o \& M_{t i} * P_{t}}{(1+d)^{i}}\right)}{C F_{t} * \sum_{i=1}^{L} \frac{P_{t}}{(1+d)^{i}}}
$$

$\mathrm{LCOE}_{\mathrm{t}}$ is the levelized cost of a typical plant installed in year t (i.e. not site specific), $K_{t}$ is the capacity-weighted average installed project cost $(\$ / \mathrm{kW}), C A P_{t}$ is the total installed capacity $(\mathrm{kW}) . i$ is a year of plant operation, running over a plant lifetime $\mathrm{L}$ of 20 years. $O \& M_{t i}$ is the annual operations and maintenance costs $(\$ / \mathrm{kWh})$, which may vary by year, $P_{t}$ is the annual output (kWh), and $C F_{t}$ is the capacity factor of plants installed in year $\mathrm{t}(\%) \mathrm{d}$ is the discount rate $(\%)$, and we use a value of $7 \%$ to match assumptions used in the U.S. National Energy Modeling System (NEMS) (EIA 2014). While changes in financing could affect trends in wind LCOE, they are neglected due to insufficient data. In addition, it seems unlikely that financing costs fall regularly over decades as in a pattern similar to incremental technological progress. 
Existing data sources report capacity factor in the form of an annual average over the fleet of wind turbines $\left(C F_{t}^{\text {fleet }}\right)$. However, for this analysis we need estimates of capacity factor of plants installed in in a given year $\mathrm{t}\left(C F_{t}\right)$, which is not available. However, we extract the required data by first producing a corrected annual fleet capacity factor $\left(\widehat{C F}_{t}\right)$ estimate, which is itself used to calculate the capacity factor of wind turbines constructed in year $\mathrm{t}\left(C F_{t}\right)$.

Given the availability of annual data on plant capacity and generation, the fleet average capacity factor, $C F_{t}^{\text {fleet }}$, can be estimated as follows:

$$
C F_{t}^{\text {fleet }}=\frac{P_{t}^{\text {fleet }}(k W h)}{\operatorname{CAP}_{t}^{\text {fleet }}(k W) * 8,760 \mathrm{hrs}}
$$

This results in an average fleet capacity factor of the cumulative average of all operating turbines, not that of new model year turbines. One could estimate the capacity factor of plants of plants added in year $t$ according to:

$$
C F_{t}=\frac{C A P_{t} * C F_{t}^{\text {fleet }}-C A P_{t-1} * C F_{t-1}^{\text {fleet }}}{C A P_{t}-C A P_{t-1}}
$$

However, this formula is not directly usable due to are year-by-year variations in wind that affect wind capacity over the whole U.S. fleet (Katzenstein et. al 2010). In addition, heterogeneity in when during a year plants come online causes year-by-year mismatches between the capacity at single point in time and the total generation of the fleet. 
Variability in wind resources and installation timing can be controlled for by using regression to estimate average annual capacity factors. The results are shown in Figure 2, these used to estimate the $C F_{t}^{\text {fleet }}$ in equation (6). We denote the smoothed fleet capacity factor $\widehat{C F_{t}^{\text {flee }}}$. The capacity factor of a given year's plants, $C F_{t}$ in equation (4), is thus estimated according to:

$<$ Figure 2 approximately here>

$$
C F_{t}=\frac{C A P_{t} * C \widehat{F_{t}^{\text {flee }}}-C A P_{t-1} * C \widehat{F_{t-1}^{\text {flee }}}}{C A P_{t}-C A P_{t-1}}
$$

where $C \widehat{F_{t}^{\text {fleet }}}$ is estimated from the linear regression in Figure 2.

\section{Capacity Factor: Effect of wind resource quality}

The next step is to adjust capacity factors for site wind quality in order to separate technological progress from changes in site quality. We use data from Lawrence Berkeley National Laboratory that provides reference wind quality for individual years (Table 2), which we compare to the gross capacity factor in the base year 1999. The annual wind quality is then indexed from that base year to create a capacity factor adjustment. Generally, the wind quality index has decreased, meaning that newer turbines are usually placed at locations with lower wind resource, presumably because the highest quality wind sites are used first. This decline in wind 
quality is external to technological progress in turbine design and should be corrected for in the data. This paper adjusts the dataset to remove the effect of wind quality changes across all years by dividing each year's CF by the index, using this equation:

$$
C F_{t}^{*}(\text { constant site quality })=\frac{C F_{t}}{W_{t}}
$$

where $C F_{t}{ }^{*}$ is the final treated capacity factor of plants built in year $\mathrm{t}, C F_{t}$ is the individual annual CF from equation (7) in year $\mathrm{t}$, and $W_{t}$ is the LBNL wind index for year t. Conceptually, $C F^{*}$ is the effective capacity factor if all turbines were installed on 1999 wind quality sites. We make the assumption that prior to 1999 the index remains at 1 . This is justified by the fact that the prior annual installations were small (less than $500 \mathrm{MW}$ total) and we assume that the quality of wind sites was not the primary limiting factor in site selection. This calculation assumes that existing turbines continue operating with the same capacity factors and thus neglects the effect that retirements have on $C F_{t}{ }^{*}$. With most generation technologies, this would be an issue. However, with wind, the scale of retirements is significantly smaller than the scale of new installations in a given year (due to the exponential growth in wind deployments), so significant deviation is not expected.

<Table 2 approximately here>

\section{Capital Adjustments}

Our final adjustment takes into account the effect that changes in international currency trading and the cost of raw materials (ex. steel) have on the capital costs of turbines. There are other materials costs such as concrete in the foundation and copper in interconnections, but these 
are not included. As with the other corrections, our interest in technological improvements in wind generation calls for isolation and removal of these extraneous effects. The analysis leverages Bolinger and Wiser's 2011 work detailing temporal changes in different components of capital costs. Our approach replicates the currency movements and material price fluctuations that their work introduced and expands it to more years. The results are then subtracted from the annual average capital costs, using the following equation:

$$
K_{t}^{*}=K_{t}-M_{t}-C M_{t}
$$

where $K_{t}^{*}$ is the adjusted capital cost, $K_{t}$ is the original capital cost, and $M_{t}$ and $C M_{t}$ are the cumulative fluctuation of material prices and currency movements in year $\mathrm{t}$, respectively. The variables are all in $\$ / \mathrm{kW}$.

The capital cost of wind can be broken down into component parts. Bolinger and Wiser use this approach to identify the driving forces behind increases in wind's capital cost (Bolinger and Wiser 2011). For material cost, they identified the mass required for 5 different materials (steel, fiberglass, iron, copper, aluminum) used in the construction of a turbine and tracked the commodity price from 2002-2010. The variation in the commodity price weighted by the turbine mass is then isolated. Additionally, the fluctuation of the US dollar compared to foreign currencies was examined because many of the turbines during this time period were imported or had imported components. The approach is described briefly below, but for further elaboration we direct the reader to the original work (Bolinger and Wiser 2011).

Our approach takes the same US International Trade Commission's import values for towers, wind power generating sets, generator parts, and parts for engines and motors used in the 
paper (ITC, 2016). Next, the Federal Reserve's foreign exchange rates are collected for countries that have significant trade in the above categories (FR, 2016). For Germany, Spain, and Italy, their historic currencies are tracked up until 1999 when the Euro was established. In that year, to avoid issues with the merging of the currencies, an average of the year before and after is used for each year. Brazil was also added as a trading partner as it had large percentage of trade with the US in the 1990's. For Mexico's currency crisis in the early 1990's, a fixed price was used because exchange rates are not available. The selected countries' trade value is used to create a percentage of total trade and normalized to total add up to $100 \%$.

Next, the percentage of total imports is created for the time series using Bolinger and Wiser's estimates for 2001-2013 and increasing the percentage of imports by $2 \%$ every year before 2001. The turbine value is applied to this percentage to get total value affected by trade, and then distributed by country percentage to get the value from each nation for that year. This value is then adjusted into the foreign currency and adjusted back into USD from the next year in order to find the currency effect for each year. These effects are summed and reduced by half, as in the paper's methodology, to account for pass through effects when companies don't actually experience the currency market effect. The data for this process is available in the supplement.

For the material section adjustment, we use a simplified version of the Bolinger and Wiser methodology. Specifically, we continue to use the material composition of their benchmark turbine for the whole timeframe, essentially fixing the turbine design. This is primarily due to a lack of an alternative. We believe this is acceptable because the increase in size has generally kept pace with the improved efficiency, so the resulting $\mathrm{kg} / \mathrm{kW}$ ratio should be fairly consistent (Wiser and Bolinger, 2014). Additionally, where the Bolinger report focused on 
2001 as their starting point, this analysis instead compares the annual price changes to a 1990 start date.

To replicate Wiser and Bollinger's methodology, we start with price data for the same five major materials treated in their work. We use the Bureau of Labor Statistic's Producer Price Index data to adjust the price data for the five materials to get prices in $\$ / \mathrm{kg}$ (BLS, 2016). This is then combined with the $\mathrm{kg} / \mathrm{kW}$ data from the paper's benchmark turbine. The results is the value of these materials in a $\$ / \mathrm{kW}$ percentage. This is compared to the 1990 start year component to estimate the increase from material cost changes.

Energy price fluctuations are addressed in the Bolinger and Wiser work. However, we neglect to use this portion of their analysis due to a lack of available Lifecycle Analysis information. The risk of double counting embodied energy already covered by the material accounting was high and, as the least significant exogenous factor, the gains were not considered to be worth the additional uncertainty.

The results from this analysis are summarized in Table 3. It shows the average annual impact from the capital adjustment for the portions before, during, and after the Bolinger and Wiser report. As the capital cost has been estimated from limited data for the 1990-1998 years, we cannot simply apply the adjustments to the result. Instead, we apply the capital adjustments to the original data and re-estimate their value for these years. For more detailed information and the source and output data, refer to the supplement.

$<$ Table 3 approximately here>

\section{Results}

Four wind experience curve models are tested: A. The traditional Power Capacity model, B. an Energy model, C. a Wind Quality Adjusted Energy model and D. the Full Model 
that accounts for energy, wind quality, and exogenous capital fluctuations. As each subsequent treatment is applied to the model, the results show both improved fit to the learning model and become more robust against assumptions for start and end year. Figure 3 shows the estimated global learning curves for the four models examined. The results show a progression of improved fit as additional factors are accounted for, though the inclusion of capital adjustments shows a negligible statistical improvement.

$<$ Figure 3 approximately here>

We introduce an additional empirical test of the model, one that could be extended to other learning curve analyses: sensitivity of learning rate to start and end years. To test sensitivity of each model to start date, the end year is set at 2015 and the start year is varied between 1990 and 1996. The resulting learning rates are plotted for each model in Figure 4. To test sensitivity of each model to end year, the start year is set at 1990 and the end year is varied from 2000-2015, shown in Figure 5.

For the Power Capacity Model (A), varying start and end year changes the learning rate significantly, with results ranging from $-0.2 \%$ to $9 \%$ (see Figures $4 \& 5$ ). Models B, C, and D show progressively lower sensitivity to start and end year. The improvement from the Power Capacity to the Energy model is the most dramatic. Depending on start and end years, the Full Model produces learning rates between $8.2 \%$ and $10.7 \%$. Including the additional uncertainty due to the confidence intervals from the earlier regressions, we obtain a range for learning rates of $7.7 \%$ to $11.2 \%$. We choose $\mathrm{LR}=9.8 \%$ as a preferred estimate because it is the result when all available data are used and is a central estimate in the range of learning rates generated by changing start and end year. 
<Figure 4 approximately here>

$<$ Figure 5 approximately here $>$

To explore the effects of geographic scope on learning rates, the four models are tested again using U.S. cumulative production. As seen in the summary results in Table 4, the learning rates for the U.S.-only model are considerably higher than the global model. The reason for higher U.S. learning rates is that wind power has been growing much faster globally than in the U.S. In particular, between 1990 and 2015, cumulative generation in the U.S. grew by a factor of 113, while global generation grew by a factor of 578. The U.S.-only B,C,D models are empirically robust, with r-squared in the $93-96 \%$ range. While one might consider using a U.S. (or other nation)-only model, note that the learning rate in this case measures not only domestic technological progress, but also implicitly includes cost reductions driven by other nations adopting the technology. Any conclusions drawn and use in forecasting must account for this additional scope of the model.

<Table 4 approximately here>

There are a number of caveats associated with these results. First, because early data on capital and O\&M costs are sparse, modeling was done to find a "best guess" for 1984-1997, but the resulting values are decidedly uncertain. To bound the error on O\&M, we found that assuming a constant O\&M costs of $\$ 50 / \mathrm{kW}$-year yielded learning rates that were $1 \%$ lower than the base case. Second, financing and grid stability costs are excluded from the analysis. These affect the economic value delivered with wind power and each have their own trajectory. Third, U.S. price 
data and LCOE results are being used as proxies for global values, so locations where wind costs diverge significantly from the U.S. may yield different results.

Comparing our learning rate with prior literature, our range falls within the bounds of prior studies (Figure 1), towards the center of the range. We established that the temporal stochasticity of the capital cost model is high and yields low learning rates for later starting years of data because it neglect the value of capacity factor improvements. Narrowing the consideration to only LCOE-based models, the range of prior learning rates is 12-32\% (IEA 2000; McDonald and Schrattenholzer 2001; Neij et al 2003). Our learning rates are smaller because we are using a global model, while the other works treat sub-regions. Most importantly, we demonstrate that learning rates for wind between $-1 \%$ and $31 \%$ can be acquired, depending on date range and location, but that the most robust model has much less sensitivity to these assumptions.

\section{Forecasting Wind Costs:}

When coupled with expected future global wind adoption rates from the IEA New Policies Scenario (IEA 2013), we forecast future wind power prices by assuming that our historical learning rates (7.7\%-11\%; best estimate of 9.8\%) persist to 2030. Results are shown in Figure 6, alongside EIA forecasts of costs for coal and natural gas-based electricity. The price of wind power falls to the range of 4.1-4.5 cents/kWh. This makes the LCOE of wind in 2030 highly competitive with expected prices of new coal and natural gas generation. This constitutes a $42 \%$ reduction in LCOE between 2011 and 2030, higher than the 20-30\% reduction described in the IEA report Past and Future Cost of Wind Energy (Lantz et al 2012). Another relevant comparison is a recently published expert elicitation study of future costs of wind power, which yielded a range of future learning rates between $10.5 \%$ and $18.6 \%$ (Wiser et al 2016). While 
there is overlap in results from learning curves and expert elicitation, learning curves are considerably less bullish on prospects for cost reductions.

$<$ Figure 6 approximately here $>$

\section{Conclusions and Policy Implications}

We have shown that the wide range in learning rates obtained in prior experience curve modeling of wind power can be explained by a combination of model choice (capacity versus generation), start and end years of data-sets, and geographical scope. Controlling for these factors by using a generation-based global model significantly narrows the resulting range of learning rates. There is a widespread need for more reflective analysis of the interaction between forecasting techniques (experience curve or otherwise) and results. The concepts that we use here - the focus on LCOE and investigation of sensitivity to date ranges and geographical areas - could be applied to a variety of technologies (Rubin et al 2015).

Forecasting future costs based on our experience curve yields an optimistic perspective for wind power competing with fossil fuel-based electricity. However, any forecast is uncertain. The two central assumptions in our forecast are, first, that future cost reductions in the next two decades follow the pattern of the previous two and, second, that continued global adoption of wind will help drive down costs. Also, as the forecasts are derived from site-aggregated data, they do not address how wind costs will vary from site-to-site. While uncertain, the experience curve approach does provide an empirical argument that continued public support of wind can deliver long-term public benefits through cheaper wind electricity.

\section{Acknowledgements}


This work was supported by the Civil Infrastructure Systems program of the National Science Foundation (grant\# CMMI 1436469). The authors thank Ryan Wiser at Lawrence Berkeley National Laboratories for providing detailed data and the reviewers for formative comments.

\section{References}

Anon (2016). Anonymous source suggested $\$ 50 / \mathrm{kW}$-yr for baseline operations and maintenance costs.

Arrow, K.J., 1962. The economic implications of learning by doing. The review of economic studies, pp. $155-173$

Black \& Veatch, 2012. Cost and Performance Data for Power Generation Technologies. Prepared for National Renewable Energy Laboratory. February, 2012.

BLS, 2016. Producer Price Index . US Bureau of Labor Statistics, http://www.bls.gov/data/

Bolinger, M., Wiser R., 2011. Understanding Trends in Wind Turbine Prices Over the Past Decade.

LBNL-5119E. Berkeley, California: Lawrence Berkeley National Laboratory.

Curtright, Aimee E., M. Granger Morgan, and David W. Keith. "Expert assessments of future photovoltaic technologies." Environmental science \& technology 42.24 (2008): 9031-9038.

DOE, 2015. Wind Vision: A New Era for Wind Power in the United States. Department of Energy, Wind and Water Power Technologies Office.

EIA, 2014. Annual Energy Outlook 2014. U.S. Department of Energy, Energy Information Administration. 
EIA, 2009. Annual Energy Outlook (AEO) 2009. Energy Information Administration (EIA), U.S.

Department of Energy. March 2009.

EIA, 2015a. Assumptions to the Annual Energy Outlook 2015. Energy Information Administration (EIA), U.S. Department of Energy. September 2015

EIA, 2015b. Levelized Cost and Levelized Avoided Cost of New Generation Resources in the Annual Energy Outlook 2015. Energy Information Administration (EIA), U.S. Department of Energy. June 2015

EIA, 2016a. NEMS Documentation. U.S. Department of Energy, Energy Information Administration. URL: https://www.eia.gov/forecasts/aeo/nems/documentation/

EIA, 2016b. Electricity Data Browser. U.S. Department of Energy, Energy Information Administration.

EIA, 2016c. International Energy Statistics, Energy Information Administration. URL: https://www.eia.gov/beta/international/

Ek, K., Söderholm, P., 2010. Technology learning in the presence of public R\&D: the case of European wind power. Ecol. Econ. 69, 2356-2362.

EPA, 2009. Data from Integrated Power Model (IPM), ICF International. U.S. Environmental Protection Agency (EPA).

EPA, 2010. Data from Integrated Power Model (IPM), ICF International. U.S. Environmental Protection Agency (EPA).

EPRI. 2011. Program on Technology Innovation: Integrated Generation Technology Options. Electric Power Research Institute (EPRI), Palo Alto, CA: 2011. 1022782.

Fingersh, L., M. Hand, A. Laxson., 2006. Wind Turbine Design Cost and Scaling Model. US Department of Energy, National Renewable Energy Laboratory. NREL/TP-500-40566 
FR, 2016. Historical Foreign Exchange Rates. US Federal Reserve, https://www.federalreserve.gov/releases/h10/hist/default.htm

GWEC, 2015. Global Wind Report Annual Market Update 2015. Global Wind Energy Council.

Ibenholt, K., 2002. Explaining learning curves for wind power. Energy Policy 30, 1181-1189.

IEA, 2000. Experience curves for energy technology policy. International Energy Agency, Paris, France, ISBN: 92-64-17650-0.

IEA, 2013. World Energy Outlook 2013, International Energy Agency, Paris, France, ISBN: 978-92-6420130-9

IEA 2015. IEA Wind 2015 Annual Report (and earlier years). ISBN 978-0-9905075-3-6. International Energy Agency: Paris

ITC, 2016. Interactive Tariff and Trade DataWeb. US International Trade Commission, https://dataweb.usitc.gov/

Jamasb, T., Köhler, J., 2007. Learning curves for energy technology: a critical assessment. In: Grubb, M., Jamasb, T., Pollitt, M.G. (Eds.), Delivering a Low Carbon Electricity System: Technologies, Economics and Policy. Cambridge University Press.

Junginger, M., Faaij, A., Turkenburg, W.C., 2009. Cost reduction prospects for off- shore wind farms. Wind Eng. 28, 97-118.

Katzenstein, W., Fertig, E., Apt, J., 2010. The variability of interconnected wind plants. Energy Policy, 38, pp.4400-4410.

Klaassen, G., Miketa, A., Larsen, K., Sundqvist, T., 2005. The impact of R\&D on in- novation for wind energy in Denmark, Germany and the United Kingdom. Ecol. Econ. 54, 227-240. 
Krohn, S., Morthorst, P.-E., Awebuch, S., 2009. The Economics of Wind Energy. European Wind Energy Association, March 2009.

Lantz, E., Wiser, R., \& Hand, M. (2012). The past and future cost of wind energy. National Renewable Energy Laboratory, Golden, CO, Report No. NREL/TP-6A20-53510.

Lindman, Å. \& Söderholm, P., 2012. Wind power learning rates: A conceptual review and meta analysis. Energy Economics, 34(3), pp.754-761.

McDonald, A., Schrattenholzer, L., 2001. Learning rates for energy technologies. Energy Policy 29, 255261.

Miketa, A., Schrattenholzer, L., 2004. Experiments with a methodology to model the role of R\&D expenditures in energy technology learning processes; first results. Energy Policy 32, 1679-1692.

Nagy B, Farmer JD, Bui QM, Trancik JE ,2013. Statistical Basis for Predicting Technological Progress. PLoS ONE 8(2): e52669. doi:10.1371/journal.pone.0052669

Navigant, 2015. World Wind Energy Market Update 2015, Navigant Research, Chicago, USA, ISBN: 978-87-85092-53-3

Neij, L., 1999. Cost dynamics of wind power. Energy, 24(5), 375-389.

Neij, L., Andersen, P.D., Durstewitz, M., Helby, P., Hoppe-Kilpper, M., Morthorst, P., 2003. Experience Curves: A Tool for Energy Policy Assessment. Environmental and Energy Systems Studies, Lund University, Lund, Sweden.

Neij, L., 2008. Cost development of future technologies for power generation - a study based on experience curves and complementary bottom-up assessments. Energy Policy 36, 2200-2211. 
Qiu, Y., Anadon, L.D., 2012. The price of wind power in China during its expansion: technology adoption, learning-by-doing, economies of scale, and manufacturing localization. Energy Econ. 34, 772785.

Rubin, E. S., Azevedo, I. M., Jaramillo, P., \& Yeh, S. (2015). A review of learning rates for electricity supply technologies. Energy Policy, 86, 198-218.

Schwabe, P., Lensink, S, Maureen Hand, M. (2011) Multi-national Case Study of the Financial Cost of Wind Energy. National Renewable Energy Laboratory, Technical Report NREL/TP-6A2-48155

Söderholm, P., Sundqvist, T., 2007. Empirical challenges in the use of learning curves for assessing the economic prospects of renewable energy technologies. Renew. Energy 32, 2559-2578.

Wiser, R.H., Bolinger, M., 2015 and earlier years. Wind Technologies Market Report. U.S. Department of Energy, Washington, DC.

Wiser, R., Jenni, K., Seel, J., Baker, E., Hand, M., Lantz, E., \& Smith, A. (2016). Expert elicitation survey on future wind energy costs. Nature Energy 1, 16135.

Wright, T. P. 1936. Factors Affecting the Cost of Airplanes. Journal of the Aeronautical Sciences 3 (4): $122-128$. 


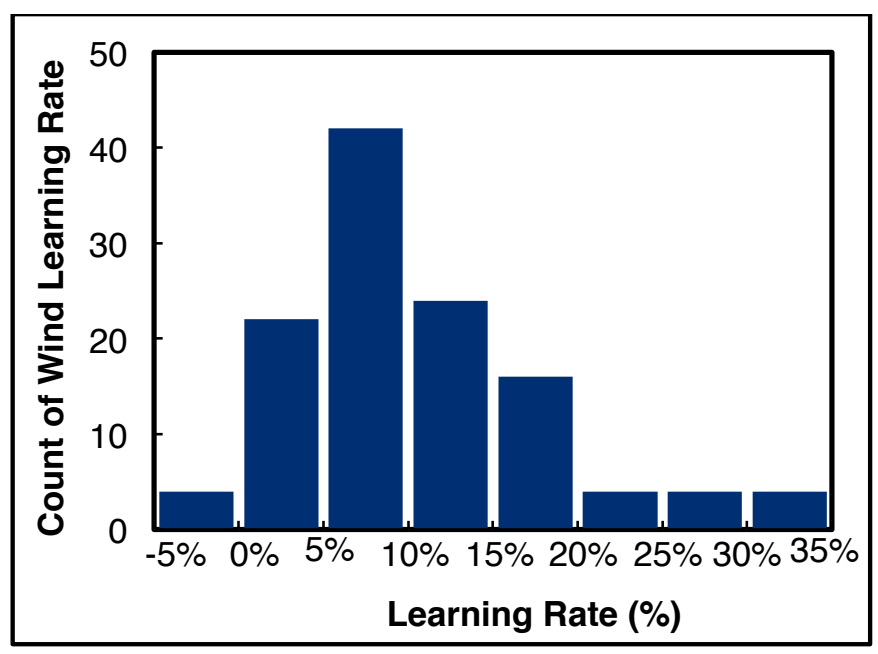

Figure 1. Wind Learning Rate Literature Summary. The count is the number of occurrences of a learning rate in the wind literature. 120 learning rates estimated in 41 publications are reported, gathered from two meta-analyses (Lindman and Söderholm 2012; Rubin et al 2015). As explored further in this paper, this wide variation arises from differences in start and end dates, which country's data are used, and what type of model is used. The dates range from 1980-2010, with many focusing on the 1990-2000 period. Countries studied include Denmark, Germany, Spain, UK, and the US, with some aggregating to a global scale via some combination of these countries. The most common model used is a single-factor experience curve focusing on capital cost and installed capacity, but multifactor models, production, and levelized cost of electricity are also represented.

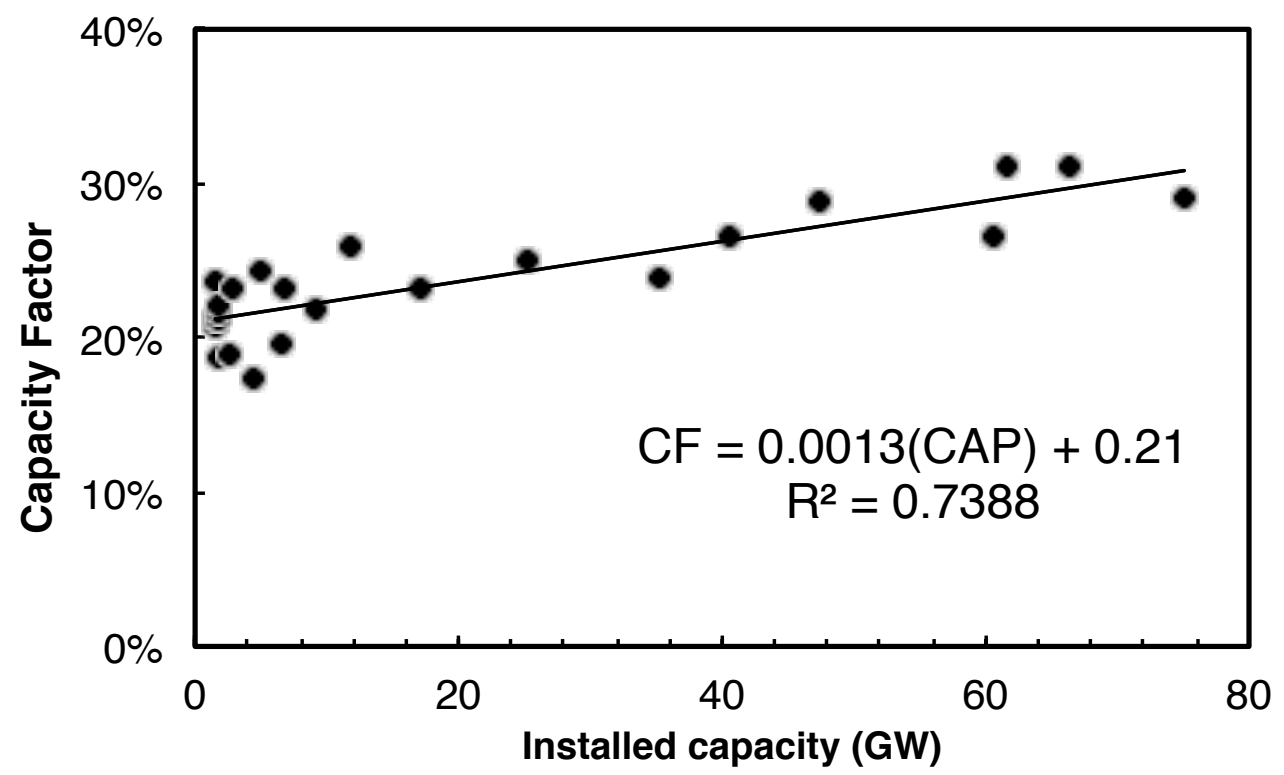

Figure 2. Calculated $C F_{t}{ }^{\text {fleet }}$ vs. Installed Capacity from 1989-2015. Regression of capacity factor versus total capacity is done to smooth out variability in capacity factors from installations coming online at the end of a year and annual variability in wind resources. 

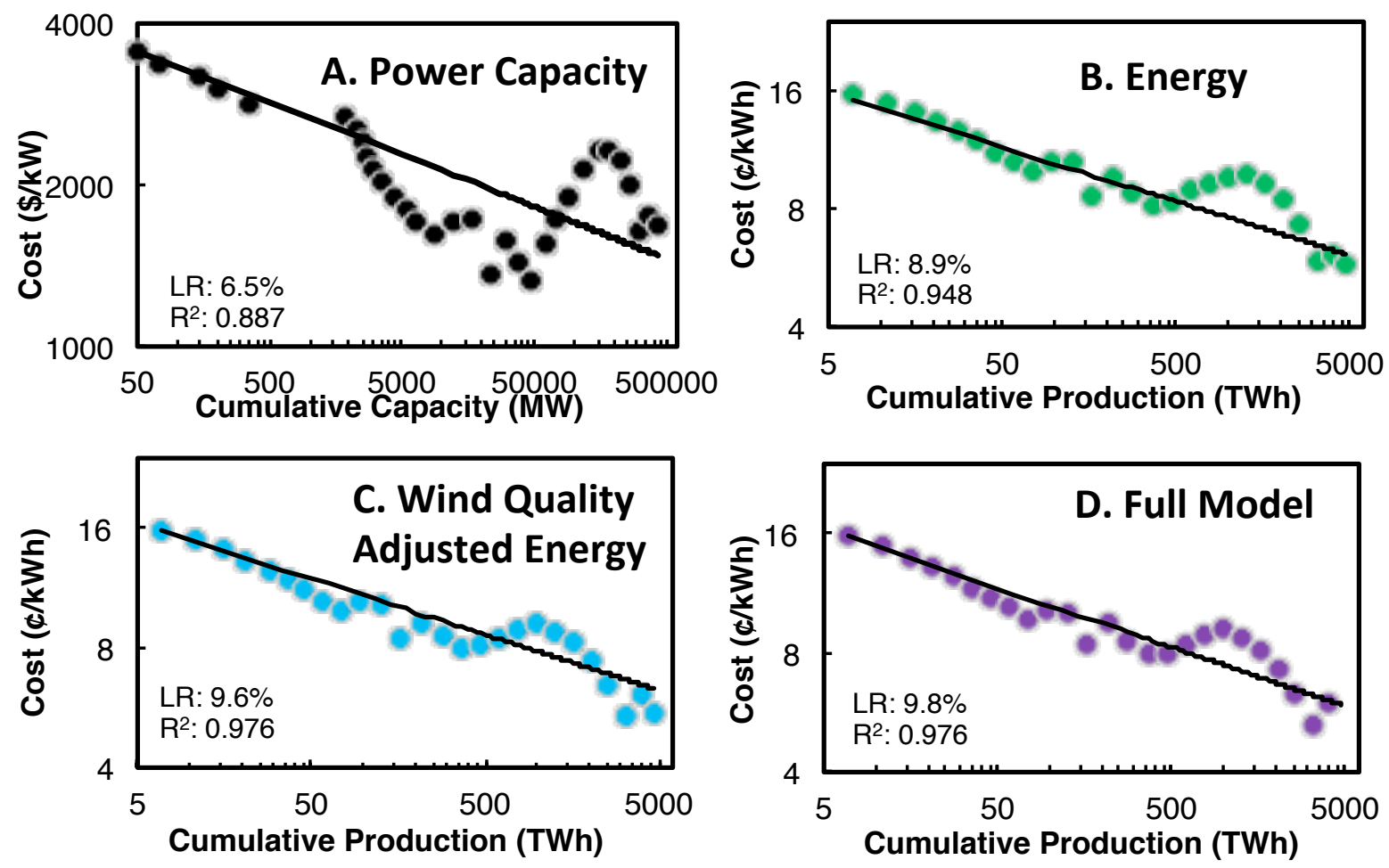

Figure 3. Global Experience Curves for wind power costs in four different models, in log-log scale, with learning rate (LR) and $\mathrm{R}^{2}$ value reported. The data for $(\mathbf{A})$ covers years 1984-2013; for models (B)-(D) the range is 19902013. 95\% confidence intervals: A: 5.7-7.3\%, B: 8.2-9.7\%, C: 9.1-10.2\%, D: 9.2-10.5\%

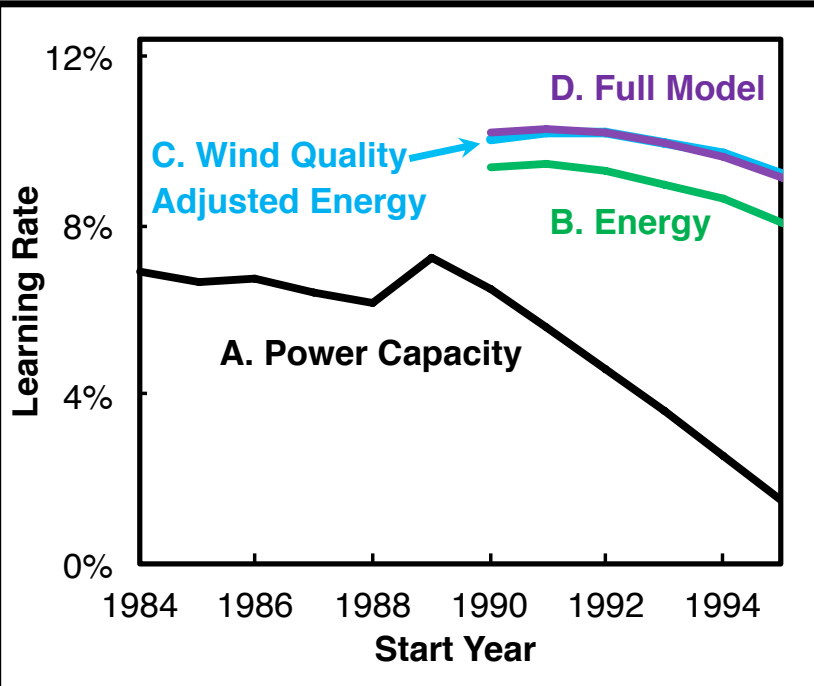

Figure 4. Learning rates as a function of wind data start date for all models. A is the traditional Power Capacity Model, B is the Energy Model, C is the Wind Quality Adjusted Energy Model, and D is the Full Model. The start year affects the estimated learning rate, but more realistic models demonstrate lower sensitivity to the date range chosen. 


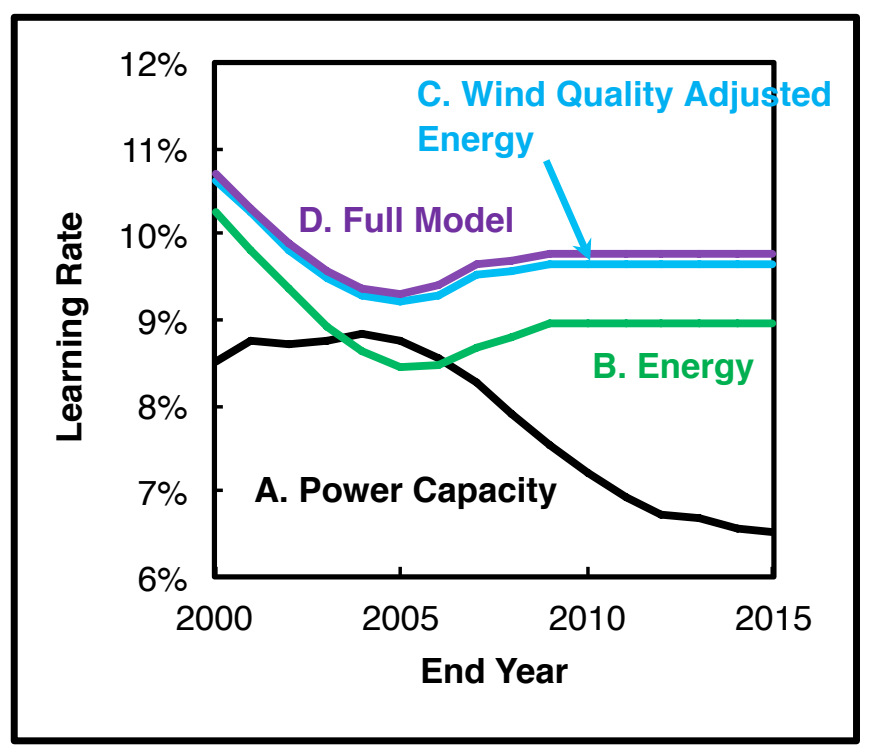

Figure 5. Learning Rates as a function of wind data end date for all models. A is the traditional Power Capacity Model, B is the Energy Model, C is the Wind Quality Adjustment Energy Model, and D is the Full Model. With each additional treatment, the estimated learning rate is less sensitive to chosen date range.

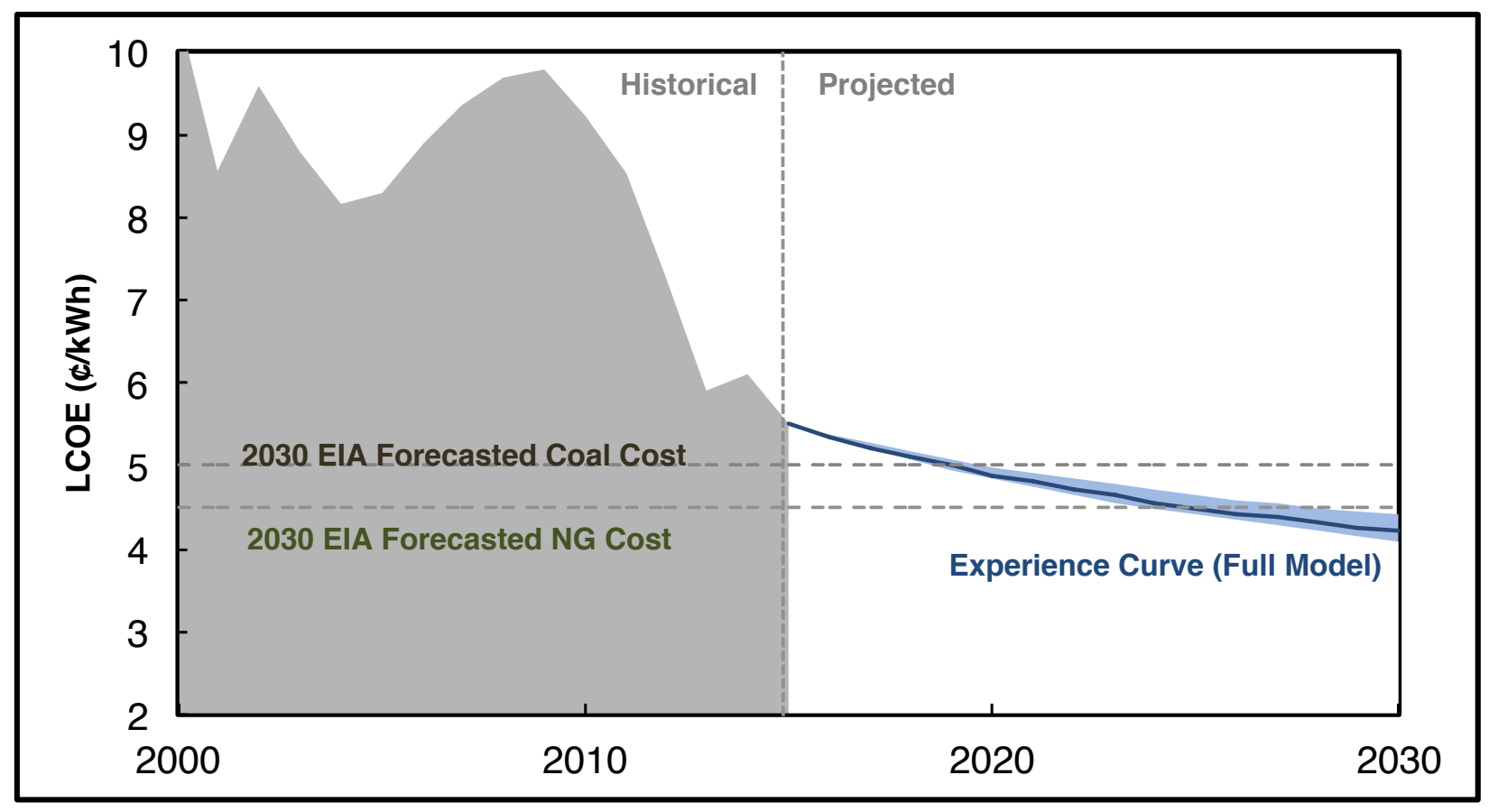

Figure 6. Historical and projected wind LCOE. The historical LCOE for wind is plotted on the left side of the graph. On the right, the projected LCOE uses our estimates using learning rates from $7.7 \%-11 \%$ (light blue area) with $9.8 \%$ as the best estimate (dark blue line). Our wedge assumes the same deployment of wind generation to the year 2030 as the International Energy Agency's New Policy Scenario, from 830 TWh in 2015 to 2269 TWh in 2030. If this progress were realized, it would make unsubsidized wind cheaper in 2030 than DOE estimated costs for all other new generation technologies (AEO 2009; Black \& Veatch, 2012; EPA 2009; EPA 2010; EPRI 2011). 